OPEN

SUBJECT AREAS:

CONSERVATION

ENVIRONMENTAL ECONOMICS

Received

24 March 2014

Accepted

14 July 2014

Published

8 August 2014

Correspondence and requests for materials should be addressed to B.C. (cuibs@bnu.edu.

\section{Economic development and coastal ecosystem change in China}

\author{
Qiang He ${ }^{1}$, Mark D. Bertness ${ }^{2}$, John F. Bruno ${ }^{3}$, Bo Li ${ }^{4}$, Guoqian Chen ${ }^{5,6}$, Tyler C. Coverdale ${ }^{2}$,
} Andrew H. Altieri ${ }^{7}$, Junhong Bai ${ }^{1}$, Tao Sun' ${ }^{1}$ Steven C. Pennings ${ }^{8}$, Jianguo Liu' ${ }^{9}$, Paul R. Ehrlich ${ }^{10}$ \& Baoshan $\mathrm{Cui}^{1}$

\begin{abstract}
'School of Environment, State Key Laboratory of Water Environment Simulation, Beijing Normal University, Beijing 100875, China, ${ }^{2}$ Department of Ecology and Evolutionary Biology, Brown University, Providence, RI 02912, USA, ${ }^{3}$ Department of Biology, University of North Carolina - Chapel Hill, CB \#3280, Chapel Hill, NC 27599, USA, ${ }^{4}$ Coastal Ecosystems Research Station of the Yangtze River Estuary, Institute of Biodiversity Science, Fudan University, Shanghai 200433, China, ${ }^{5}$ Division of Climate Change Thermodynamics and Systems Ecology, College of Engineering, Peking University, Beijing 100871, China, ${ }^{6}$ Institute of Environmental Economics and Policy Research, Beijing Normal University, Beijing 100875, China, ${ }^{7}$ Smithsonian Tropical Research Institute, Apartado 0843-03092, Balboa, Ancon, Republic of Panama, ${ }^{8}$ Department of Biology and Biochemistry, University of Houston, Houston, TX 77204, USA, ${ }^{9}$ Center for Systems Integration and Sustainability, Department of Fisheries and Wildlife, Michigan State University, East Lansing, MI 48823, USA, ${ }^{10}$ Department of Biology, 371 Serra Mall, Stanford University, Stanford, CA 94305, USA.
\end{abstract}

Despite their value, coastal ecosystems are globally threatened by anthropogenic impacts, yet how these impacts are driven by economic development is not well understood. We compiled a multifaceted dataset to quantify coastal trends and examine the role of economic growth in China's coastal degradation since the 1950s. Although China's coastal population growth did not change following the 1978 economic reforms, its coastal economy increased by orders of magnitude. All 15 coastal human impacts examined increased over time, especially after the reforms. Econometric analysis revealed positive relationships between most impacts and GDP across temporal and spatial scales, often lacking dropping thresholds. These relationships generally held when influences of population growth were addressed by analyzing per capita impacts, and when population density was included as explanatory variables. Historical trends in physical and biotic indicators showed that China's coastal ecosystems changed little or slowly between the 1950s and 1978, but have degraded at accelerated rates since 1978. Thus economic growth has been the cause of accelerating human damage to China's coastal ecosystems. China's GDP per capita remains very low. Without strict conservation efforts, continuing economic growth will further degrade China's coastal ecosystems.

oastal ecosystems are among the most valuable on Earth due to their provisioning of ecosystem services ${ }^{1,2}$. For example, salt marshes, mangrove forests and seagrass beds buffer shorelines from storm damage and erosion, store carbon, serve as critical nursery grounds for commercial shellfish and finfish, and biochemically process terrestrial runoff ${ }^{2}$. Nearly half of the world's population lives near coasts that benefit human society with access to trade, land development, oil/gas exploration, and food production ${ }^{1,3}$. This is a primary reason for the higher per capita income generally observed in coastal than in landlocked countries ${ }^{3}$.

Despite their value, coastal ecosystems are being rapidly degraded globally by human activities ${ }^{4-6}$. Industrialized overfishing, for example, has caused worldwide declines and extinctions of predatory fishes such as sharks and rays ${ }^{7}$; pollution and climate change has driven widespread collapses of coral reef ecosystems ${ }^{8}$; and coastal reclamation for agriculture and urban sprawl has led to massive losses of salt marshes and mangroves?. Most science on the changes in coastal ecosystems is focused on the role of increasing human population density ${ }^{4,5}$. Although economic growth could have similar or even greater effects (due to increased resource consumption and waste output $)^{10,11}$, the relationship between economic development and coastal human impact has been rarely examined. Moreover, human impacts on coastal ecosystems are largely unexplored in developing countries $^{12}$, which will drive much of the world's future economic growth.

Understanding the relationship between economic development and environmental degradation has long been an important goal in environmental science and ecological economics ${ }^{13,14}$. The environmental Kuznets curve (EKC) hypothesis predicts that in the early stages of economic growth, human impacts increase with per capita income, but decrease when per capita income reaches a threshold due to changes in technology ${ }^{13,14}$. Testing the EKC hypothesis has become increasingly important, as the existence of an EKC relationship would suggest that 
economic development can be a solution for environmental degradations in the future without policy intervention ${ }^{15}$. The EKC hypothesis has been widely examined for a number of drivers of environmental degradation (e.g., pollutant emissions ${ }^{15-18}$ and deforestation ${ }^{19,20}$ ) or indicators of potential impacts (e.g., resource consumption $^{21,22}$ ). Despite previous studies, however, consensus on the EKC hypothesis has not been reached, especially for developing countries $^{23}$. Also, it remain necessary to test the EKC hypothesis for individual countries to improve the development of effective region-specific environmental policies ${ }^{15}$. Furthermore, the EKC hypothesis has generally not been tested for coastal human impacts.

In China, 1.3 billion people are rapidly shifting from a largely agrarian society in the interior of the country to an industrial economy concentrated in coastal regions. Since economic reforms initiated in 1978, China has experienced unprecedented economic development ${ }^{24,25}$. China's growing economy is increasingly concentrated in coastal regions ${ }^{24,26}$. This rapid economic development provides an opportunity to examine the impact of economic development on coastal ecosystems. China's $30,017 \mathrm{~km}$ of coastlines and $348,090 \mathrm{~km}^{2}$ of seas support nearly half of its human population and 45 of its 60 major cities, sustain $>28,000$ species $^{27,28}$, and process outflow from 7 of its 9 major rivers. Several recent indicators including pollution and fisheries suggest that negative impacts on coastal ecosystems are associated with this economic development ${ }^{29-31}$. Despite evidence arising from these specific factors, the consequences of China's economic development for coastal degradation have not been holistically examined.

Here, we provide a synthesis of coastal trends and the role of economic growth in the degradation of China's coastal ecosystems since the 1950s covering both pre- and post-economic reform periods. We compiled a unique and comprehensive dataset from yearbooks, governmental and non-governmental reports, and primary literature. We included data on China's coastal economy, population, and various human impact factors. Many of these data are often inaccessible internationally (e.g., province-level data of mariculture and fertilizers). Using this dataset, we quantified trends in China's coastal population, economy, and human impacts holistically for the first time. We tested the following specific hypotheses: (1) China's coastal economy, population, and human impacts have all increased over the last six decades, but the increases were substantially faster post- than pre-economic reforms, (2) economic growth is positively related to indicators of coastal human impact temporally and spatially, and (3) China's coastal ecosystem degradation was accelerated in the post-economic reforms period.

To examine trends in China's coastal economy and population, we collected data on China's gross domestic product in its coastal regions (coastal GDP), calculated per capita GDP, and compared yearly increase rates between pre- and post-reforms. To quantify trends in coastal human impacts, we followed previous frameworks $s^{4,32,33}$ and gathered data on 15 types of human impacts in four categories: fishing, waste emissions (pollutants and $\mathrm{CO}_{2}$ ), habitat transformations and transportation disturbance. The definition and selection of these indicators are further provided in Methods. We included impacts directly related to coastal and marine industries that consume species and ecosystem services or generate physical disturbances (fishing, habitat transformations, and transportation disturbance). We also included impacts from both coastal and non-coastal economic activities (waste emissions). To examine the role of economic growth in accelerating coastal impacts, we first compared pre- and post-economic reform patterns, and then examined the relationship between GDP per capita and human impacts. The relationship was examined under the framework of the EKC hypothesis, using time-series (temporal evidence), cross-regional (spatial evidence) and panel data that integrated both (see Methods). Finally, we examined how increasing human impacts influenced historical patterns of coastal degradation by quantifying changes in coastal physical environments, biota (fish, red tides, corals) and habitats (wetlands and mangroves).

\section{Results}

Coastal economy and population. China's coastal GDP remained low and grew annually by $\sim 2.2$ billion USD (constant 2000 prices) between the 1950s and 1978 (Fig. 1). National economic reforms then triggered coastal GDP growth between 1978 and 2010 greater than two orders of magnitude. The coastal GDP accounted for 50\% of China's total before 1978, but grew to $\sim 60 \%$ between 1978 and 2010 (Fig. 1c). China's coastal population increased from 260 million in 1954 to 400 million in 1978, and to 590 million in 2010. But in contrast to coastal GDP, the rate of population growth did not increase with economic reform ( $\sim 6$ million per year; Fig. 1d) due to population control policies. The coastal population accounted for $40-43 \%$ of China' total population in all years (Fig. 1c). Thus in contrast to GDP, China's population did not concentrate on the coast over the last six decades. Coastal GDP per capita (GDPpc) increased less than three-fold between the 1950s and 1978, but over 18-fold between 1978 and 2010 (Fig. 1b). Approximately 15\% of the coastal GDP in 2010 was from marine and marine-related industries, and $6 \%$ from industries directly consuming marine species and ecosystem services, e.g., fisheries, transportation, tourism, and oil/gas production ${ }^{34}$.

Human impacts pre- and post-economic reforms. All of the 15 examined human impacts increased, several by orders of magnitude, during the six-decade study period (Fig. 2). Some impacts (e.g., excess watershed fertilizers, $\mathrm{CO}_{2}$ emissions, mariculture habitat transformation, and marine freight transportation) showed trajectories reflecting GDP growth. Other impacts (e.g., exclusive economic zone [EEZ] fishing, global fishing, habitat transformation for salt production [hereafter, saltpan], coastal reclamation in Shanghai and Jiangsu, and marine passenger transportation) also increased, but at lower rates. Pre- and post-reform comparisons revealed significantly higher annual increases in post- than pre-reform periods for 6 of the 10 impacts with data for both periods (at the level of $P<0.05$ ). We found no differences for the remaining 4 impacts (Supplementary Fig. S1). We did not find lower growth in post- than in pre-reform periods for any human impact. Results for per capita impacts were similar, except that coastal reclamation in Shanghai slowed down post-reforms (Supplementary Fig. S1). Current values of 6 of the 10 examined human impacts reached far above the $95 \%$ confidence intervals forecasted using pre-reform trends, 4 fell within and none fell below.

Temporal and spatial relationships between economic growth and human impact. Time-series analysis showed that 6 of the 9 human impacts with national-scale data (Table 1, Fig. 3) had an inverted Ushape relationship with GDPpc, displaying a turning point predicted by the EKC hypothesis. Turning points for fertilizers (Fig. 3b) and saltpans appeared to have been recently passed. However, those for $\mathrm{CO}_{2}$ emissions and mariculture (11000 and 6800 USD, respectively) have not, and are predicted to occur at levels much higher than current GDPpc. Turning points for fishing were likely induced by the zero-growth policy mandated since 1999 (ref. 35). Analysis excluding the post-1998 data revealed monotonic increases in fishing with GDPpc (Table 1, Fig. 3a). The other 3 impacts, all transportation related increased linearly or nonlinearly with GDPpc, except that oceangoing freight was best predicted with constant and autoregressive terms and no GDPpc. Most relationships held when population density, trade openness (an institutional policy measure) and time trend (proxy for time dependent variables including technological change) were included as explanatory variables ${ }^{19}$, and when analyzed as per capita impacts (Table 1). The exceptions were (i) $\mathrm{CO}_{2}$ emissions increased monotonically, (ii) when analyzed as per 

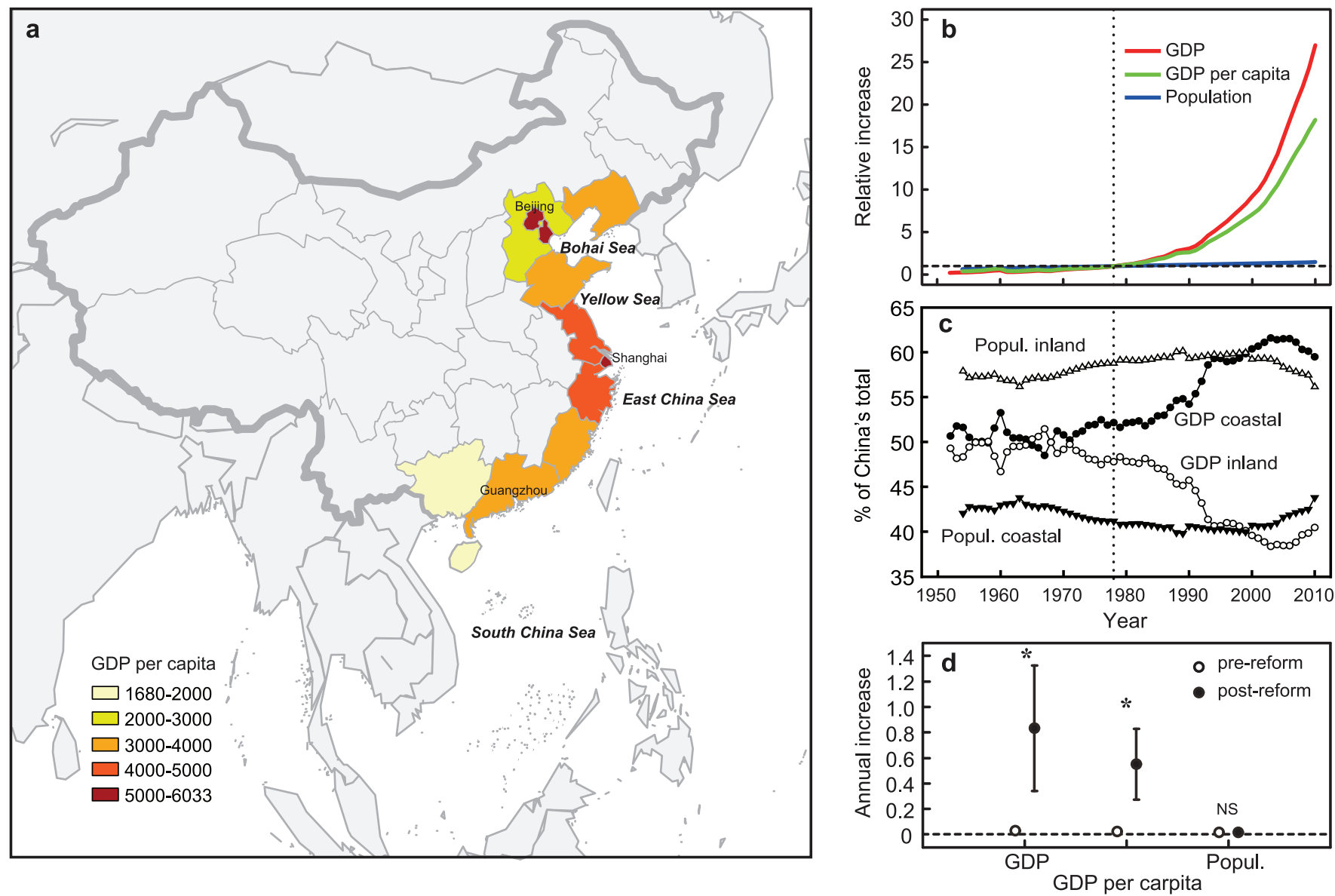

Figure 1 Trends in economy, population in coastal China. (a) China's coastal provinces examined in this study and their GDP per capita in 2010 (constant 2000 USD). (b) Relative increase over the last six decades. (c) Trends in coastal GDP and population as percentage of China's total (also shown relative to inland). (d) Yearly average increases $( \pm 95 \%$ CIs $)$ in pre- and post- reform periods. Dashed vertical and horizontal lines indicate the start of economic reform and the relative impact $(=1)$ in 1978, respectively. Differences between pre- and post-reform periods are considered significant if there is no overlap in their $95 \%$ CIs (shown with a *). The background map in (a) was created using the maps/mapproj packages of $\mathrm{R}$ ( $\mathrm{R}$ Foundation for Statistical Computing, Vienna, Austria) and Adobe Illustrator (Adobe Systems Inc., CA, USA).

capita impact, passenger transportation deceased with GDPpc, and (iii) saltpans may have varying turning points or be unrelated to GDPpc.

Cross-sectional analysis showed that regionally across China, 5 of the 9 impacts monotonically increased with GDPpc, one (mariculture) had an inversed-U shaped relationship (Fig. 3g), one (freight transportation coastal) had a U-shaped relationship (Fig. 3h), and two (fishery catch and saltpan) had no relationship (Table 1). Panel analysis integrating temporal and spatial dimensions revealed that 4 of the 9 human impacts increased linearly or nonlinearly with GDPpc, while the other 5 impacts had inversed-U-shaped relationships with GDPpc (Table 1, Fig. 3i-1). Although 3 of these 5 impacts (global fishery catch, mariculture, and saltpans) had a turning point at 900-2400 USD that appeared to have been passed, the other $2 \mathrm{had}$ turning points far higher than current levels of GDPpc.

Historical trends in coastal degradation. China's coastal ecosystems have clearly been degraded by accelerating human impacts since the 1978 economic reforms. The physical environment of China's coastal seas has changed. Surface seawater temperature and dissolved inorganic nitrogen have increased significantly in all four coastal seas, except in the northernmost Bohai Sea where seawater temperature did not change (Supplementary Fig. S2). In contrast, seawater dissolved oxygen and $\mathrm{SiO}_{3}-\mathrm{Si}$ generally decreased (Supplementary Fig. S2). No change in salinity and $\mathrm{PO}_{4}-\mathrm{P}$ was found, except in the Bohai Sea where salinity has increased.
Across China's seas, the trophic diversity and body size of marine fish did not change before 1978, but both have steadily decreased since (Fig. 4a). Harmful algal blooms have become more frequent and extensive since the 1980s, with red tides increasing from $<10$ / year before 1980 to $70-120 /$ year since 2000 (Fig. 4b). In the South China Sea, percent cover of many corals has crashed to $<15 \%$ of prereform levels (Fig. 4c). With increasing human impacts, the areas of marshes, mangroves and tidal flats have decreased. However, estuarine delta area has increased due to heavy sediment loads carried by rivers. There are indications that restoration has begun to reverse mangrove loss (Fig. 4d).

\section{Discussion}

Our study provides strong evidence for that economic development is accelerating coastal degradation in China. The effect of economic growth is seen in comparisons between pre- and post-reform data, and in our econometric analysis of human impact and GDPpc. Given that the 1978 economic reforms were a major turning point in China's economic growth ${ }^{24,25}$, our pre- and post-reform comparative analyses reveal the magnitude and pervasiveness of the escalation of post-reform coastal human impacts. Our econometric analysis found turning points for some human impacts, as predicted by the EKC hypothesis ${ }^{13,14}$. However, most of these turning points occurred recently, remain to occur far into the future, or were a direct result of institutional mandate, particularly in the time-series analysis on China's total. Our analysis therefore indicates a largely positive rela- 

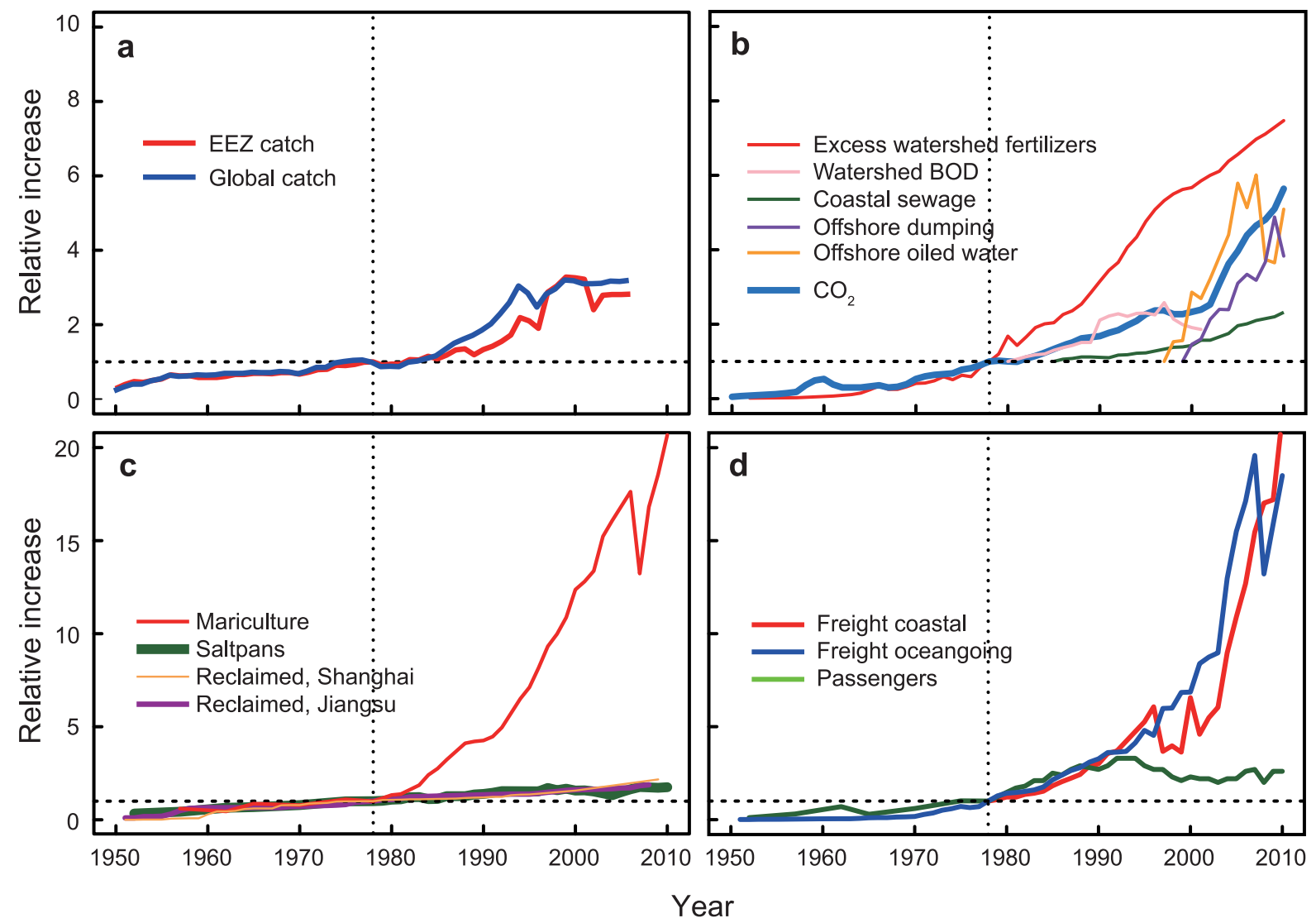

Year

Figure $2 \mid$ Trends in human impacts on China's coastal ecosystems. (a) China's fishery catches in coastal seas (exclusive economic zone, EEZ) and globally. (b) Waste emissions. (c) Habitat transformations. (d) Marine transportation.

tionship between human impact and economic growth across various impacts. This finding is consistent across temporal and spatial scales. This finding is also independent of additional explanatory variables such as population density, suggesting that economic growth alone can accelerate coastal degradation even when human population size remains constant $t^{4,5}$. We recognize that further analysis should be conducted to examine if inclusion of more explanatory variables (e.g., changes in human needs and way of life) may change this positive relation. Interestingly, as shown in the crosssectional and panel analyses, when China's regional differences were accounted for, the turning points for some impacts (e.g., mariculture) were lower than in the time-series analysis on China's total impacts. This may be due to impact transfer from high to low GDP regions ${ }^{36}$.

Accelerated coastal degradation following economic reforms is apparent across the various indicators of the physical marine environment and marine biota and habitats we examined. Direct pre- and post-reform comparisons were not feasible for some physical parameters, due to lack of consecutive pre-reform data. Studies of sedimentary records, however, indicate that deposition of coastal pollutants (e.g., heavy metals and polycyclic aromatic hydrocarbons associated with electronic and chemical industries) has intensified with economic development ${ }^{37-39}$. This lends support to our interpretation that such changes have accelerated post reforms. Furthermore, degradation of coastal ecosystems may result from combined effects of multiple human impact factors ${ }^{32,40}$. For example, in addition to accelerated coastal reclamation post economic reforms, ocean warming or sea-level rise may also play a role in the losses of corals, marshes and mangroves.

Our study has several limitations. First, we did not directly correlate indicators of coastal degradation such as wetland loss with GDPpc. Such regressions are often not feasible, as indicators of coastal degradation are not as well quantified as human impacts, with data available for only a few, non-consecutive years. And regressing human impact with GDPpc, as in the present study, is a widely utilized approach in the literature (e.g., pollutant emission studies $^{16-18}$ ). Second, while our study presents the most comprehensive and quantitative documentation of human impacts on China's coastal ecosystems to date, some other human impacts and coastal responses remain unquantified. The strength of our findings lies in the consistency among different data sources and multiple analytical approaches. Additionally, our study focuses on coastal impacts of economic development. It should be recognized the trade-offs between economic development and human impacts. Economic growth can remain important to improve human well-being in less developed regions such as in China ${ }^{41}$, and some levels of human impacts associated with economic growth may be acceptable. However, our study shows that coastal human impacts post-reform in China have already led to consistent, widespread and severe coastal ecosystem changes at high rates (e.g. $>85 \%$ losses of corals, fish diversity declines and red tide booms across China's coastal seas).

We conclude that the recent economic growth has been the cause of accelerating human damage to China's coastal ecosystems. The overall trajectories for China follow trends of developed countries ${ }^{4,42}$. However, some impacts in China, especially fishing and pollution, have surpassed current (and likely historical maximum) levels of many developed and developing countries ${ }^{33,43}$. China's coastal resources appear to be limiting relative to its economic demands. Furthermore, China's GDPpc, even in more developed coastal provinces, remains very low (2000-4000 USD) and short of many theoretical EKC turning points. This implies that continuing economic growth will lead to further increases in human impacts and threats to coastal biodiversity. 
China has adopted a series of coastal conservation measures since the 1980s, including legislation for marine environmental protection, fishing moratoriums, establishing marine protected areas, and funding coastal research and restoration ${ }^{31,35,44}$. Unfortunately, these measures are often poorly enforced and compromised by conflicts with economic development (examined in detail in refs. 35, 44, 45). For example, China's marine protected areas, though fully protected in law, are often implemented as multiple-use areas; the location, establishment and management of the marine protected areas often lie in the responsibility of local governments that are driven by local economic interests rather than by strategic conservation objectives ${ }^{44,45}$. Moreover, China's environmental protection laws/regulations are not comprehensive or strict enough, and in many cases the laws/ regulations that existed are ignored, therefore being ineffective in protecting the environment ${ }^{35}$. Last but not least, a systematic, national system of environmental management in the coastal zone of China has been lacking. We suggest that a stronger conservation ethic (including a long-term and systematic plan) and shift in thinking from prioritizing short-term economic development to considering how ecosystem services sustain economic growth would promote conservation of coastal ecosystems. To balance economic growth and the capacity of China's coastal ecosystems to sustain progress, innovative, integrated assessments of the health of coupled human-ocean ecosystems would be an important next step, as recently demonstrated globally ${ }^{46}$ and for Brazil at the state scale ${ }^{47}$. To sustain its economic ascendance, China needs innovation and leadership that will allow it to depart from the trend of devaluating natural resources that historically has plagued developing nations.

\section{Methods}

Economy and population. To quantify trends in economy and population $(>0.5$ year residential, due to the floating population issue ${ }^{48}$ ) in coastal China over the last six decades, we extracted GDP (1952-2010) and population (1954-2010) data from China's National Database of Statistics (http://stats.gov.cn) for each of the 11 coastal provinces/province-level cities: Liaoning, Hebei, Tianjin, Shandong, Jiangsu, Shanghai, Zhejiang, Fujian, Guangdong, Guangxi and Hainan (GDP and population data of other provinces and the total of China were also extracted for use in following sections). Due to historical changes in administrative boundaries between Hebei, Tianjian and Beijing, we also extracted those data for Beijing. We did not include Taiwan, Hong Kong and Macau where $(i)$ governmental policies enforced in mainland China did not apply and (ii) consistent, long-term data were unavailable. Coastal GDP (converted to constant 2000 USD) and population were calculated as the sum of the coastal provinces'. We defined coastal GDP and population on the basis of province, rather than within some distances of the coast, because those data were better developed on a per province basis. Long-term GDP data of specific marine industries were unavailable (available only for recent years; www.soa.gov.cn/), precluding analysis of those data.

We estimated yearly average increases in coastal GDP and population in two periods: pre- and post-reform in 1978, using AUTOREG in SAS 9.3 that estimates and forecasts linear regression models for time series data with autocorrelated error items. Stepwise autoregressions with a large order of the autoregressive error model (NLAG $=5$ ) were used.

Human impacts. Temporal trends for four categories of major types of human impact (fishing, waste emissions, habitat transformations and transportation disturbance) were quantified by collecting data from published databases and literature. Detailed definitions and selection of these data are given in Supplementary Methods and Table S1. Briefly, for fishing, we considered China's fish catch in exclusive economic zones and globally. For waste emissions, we considered three sources of land-based pollutant discharge (excess watershed fertilizers, watershed industrial water pollution, and coastal sewage) and two sources of ocean-based pollutant discharge (offshore waste dumping and oilfield production wastewater). We also collected data on $\mathrm{CO}_{2}$ emissions, the cause of ocean warming and acidification and sea level rise. We did not analyze trends in these or other aspects of global climate change as they have been well-developed globally (see ref. 49). For habitat transformations, we quantified trends in the human uses of coasts and seas for salt production pans and mariculture, and for coastal reclamations in Shanghai and Jiangsu. For transportation disturbance that can lead to ship strikes of large animals, noise pollution, etc ${ }^{50}$, we collected the following transportation data as proxies ${ }^{33}$ : total turnover volume of marine passenger (passenger-kilometer, pkm), coastal freight and oceangoing freight (ton-kilometer, tkm). All data sources (with definitions, available periods, limitations, etc.) are given in Supplementary Table S1.

The role of economic growth on human impacts. We used two approaches to examine the role of the economic boom in accelerating human impacts on China's 
Time-series analysis
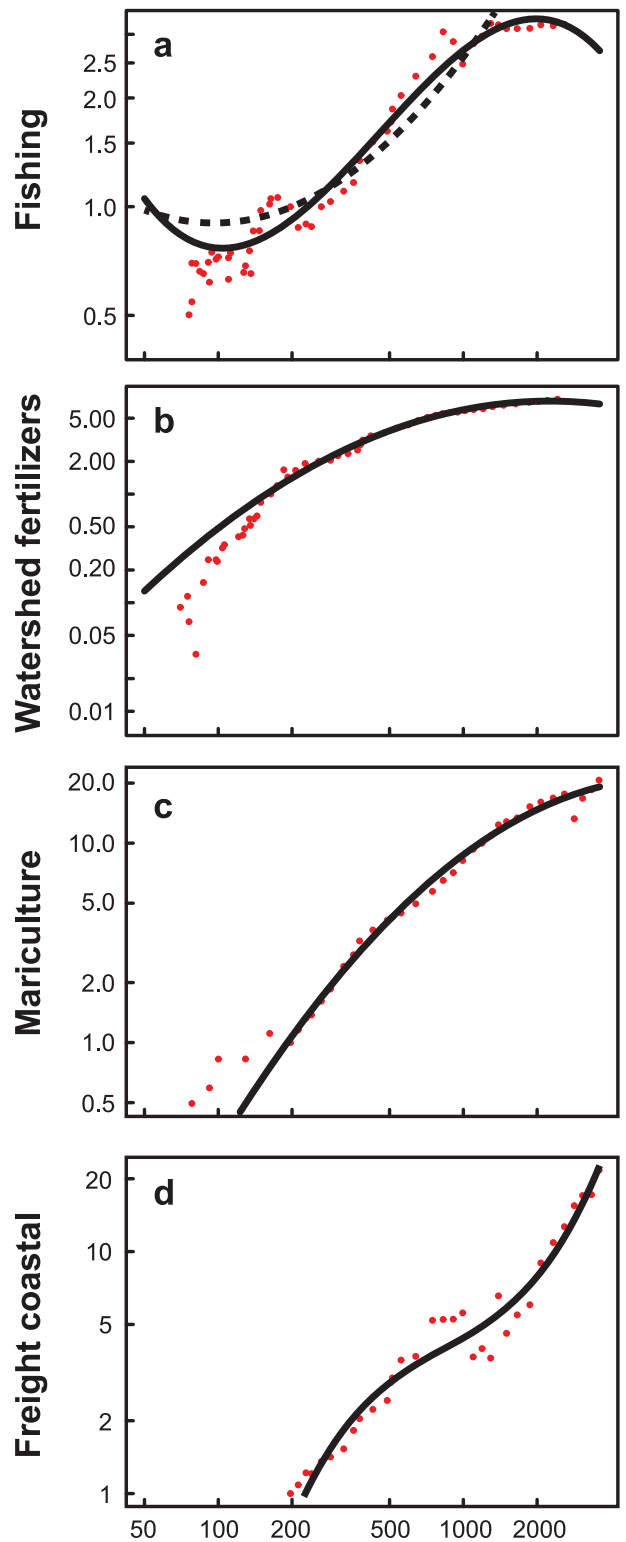

Cross-sectional analysis
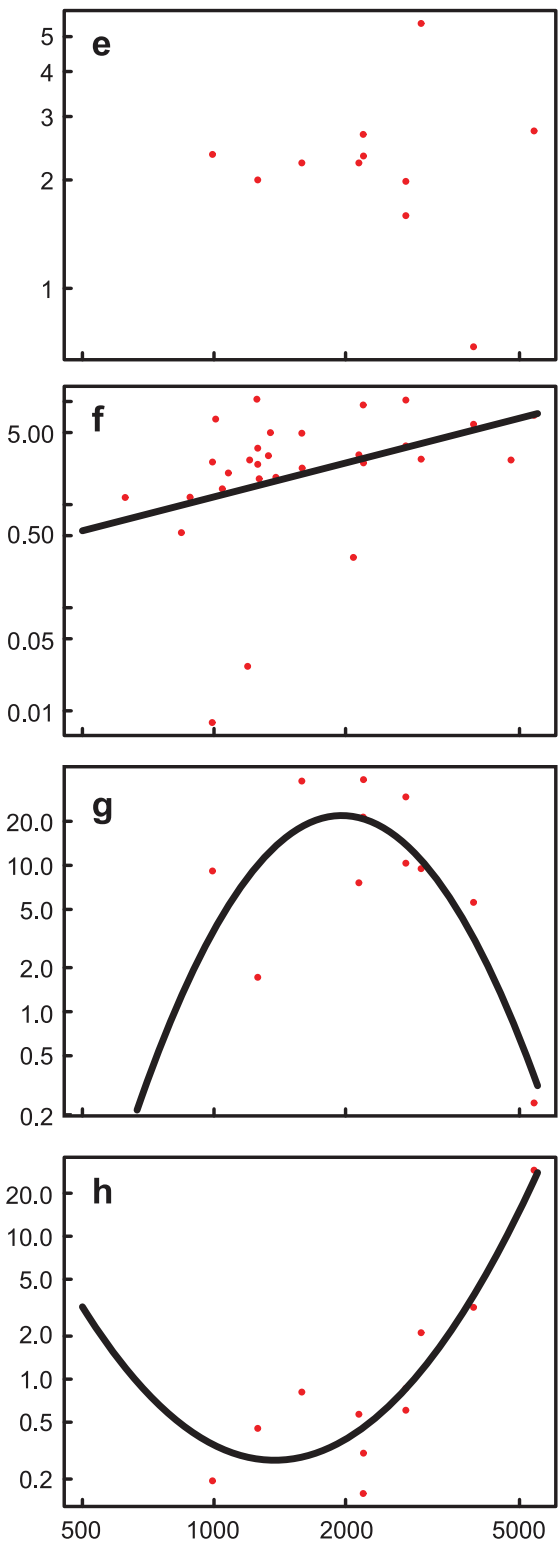

Panel analysis
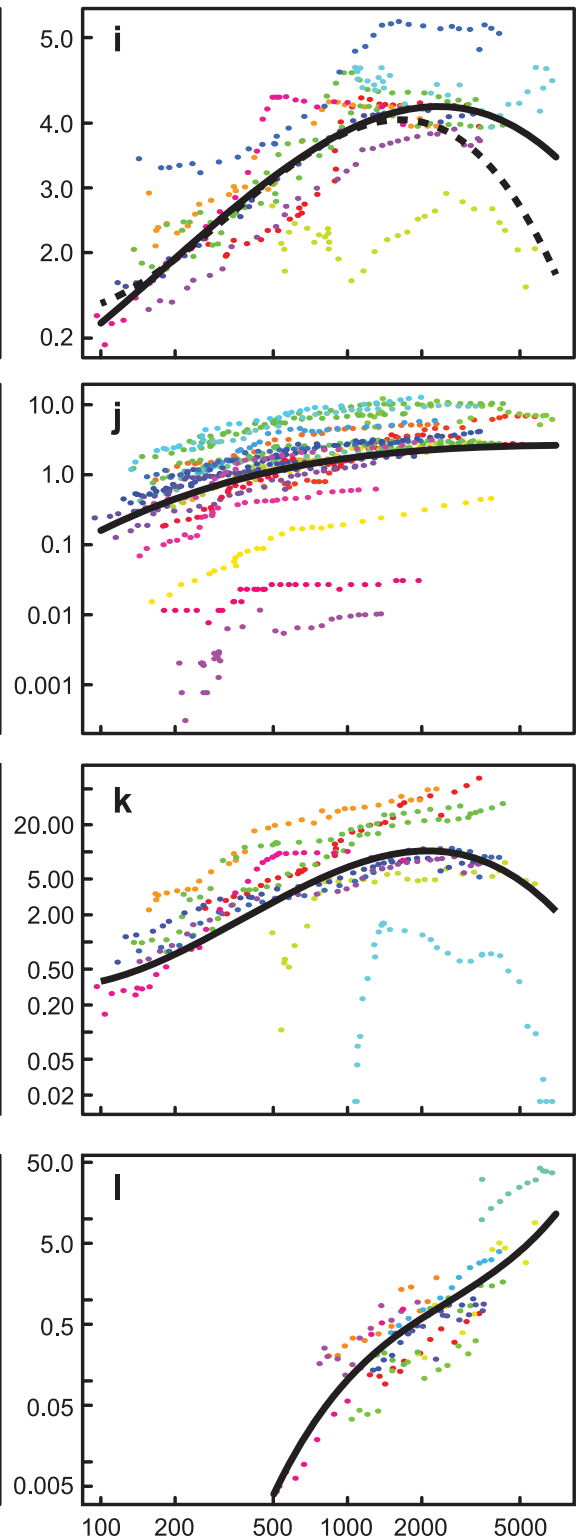

GDP per capita (constant 2000 USD)

Figure 3 Relationship between economic growth and four selected human impacts: fishing, excess watershed fertilizers, mariculture, and coastal freight transportation. (a-d) Time series analysis on total impact; $(\mathrm{e}-\mathrm{h})$ panel analysis; and $(\mathrm{i}-\mathrm{l})$ panel analysis (data points of the same color are from the same region). Impacts are relative values. For the time-series analyses, impacts in 1978 were set to be 1, and for the other analyses, impacts averaged across regions in the earliest year available were set to be 1 . Dashed lines in (a) and (i) excluded data since 1999. All relationships shown are significant at the level of $P<0.05$. See detailed statistics and other relationships in Table 1 .

coastal ecosystems. First, we estimated yearly average increases (and 95\% CIs) in ten human impacts with both pre- and post-reform data (see Supplementary Fig. S1) using autoregressive models (as described above) and determined whether they differed between pre- and post-reform periods (estimated $95 \%$ CIs do not overlap ${ }^{51}$ ). Autoregressive models can deal with missing values (common in some of our prereform data) and account for the autocorrelation of errors in time series data that violate ordinary linear regression models. This procedure is considered to be flexible and powerful ${ }^{52}$. The analysis was done for both total and per capita impact. For EEZ and global fishing, as fishery catches were mandated as constant since 1999 ("the zero-growth policy"; see ref. 35), we also estimated their yearly average increases in post-reform periods without the implementation of this policy by excluding the post1998 data. Additionally, we forecasted the impacts for post-reform periods using autoregressive models of pre-reform periods.

Second, we examined the relationship between economic growth and human impacts under the framework of the EKC hypothesis. This analysis was done using EViews 7 and log-cubic models (ln transformed to reduce data heteroscedasticity $^{16-18}$ ). To improve the robustness of our results, the analysis was done using time- series, cross-sectional (i.e., provinces) and panel analyses (a summary of the data used for cross-sectional and panel analyses was given in Supplementary Table S2). To address the concern that the relationships can be sensitive to inclusion of additional variables besides GDP, we ran the time-series analysis with and without population density, trade openness (defined as the sum of merchandised imports and exports divided by GDP; World Bank data) and time trend as additional explanatory variables $^{19}$. The shape and turning points of the relationships were determined ${ }^{17,18}$.

Time-series analysis: Nine human impacts with available long-term $(>=30 \mathrm{a})$, national-scale data (see Supplementary Table S1) were used, in their total and per capita amount. For fishing, we excluded the post-1998 data and reran the analysis to address the influence of the zero-growth policy. The following EKC model was used:

$$
\ln y_{t}=\beta_{0}+\beta_{1} \ln x_{t}+\beta_{2}\left(\ln x_{t}\right)^{2}+\beta_{3}\left(\ln x_{t}\right)^{3}+\beta_{4} \ln p_{t}+\beta_{5} \ln o_{t}+\beta_{6} T_{t}+\varepsilon_{t}
$$

where $y$ is a impact driver, $x$ is GDP per capita, $p$ is population density, $o$ is trade openness, $T$ is time trend, $t$ is time (year), $\beta_{0}-\beta_{6}$ are the coefficients to be estimated, and $\varepsilon$ is the error term. To estimate the coefficients, we ran the model without 

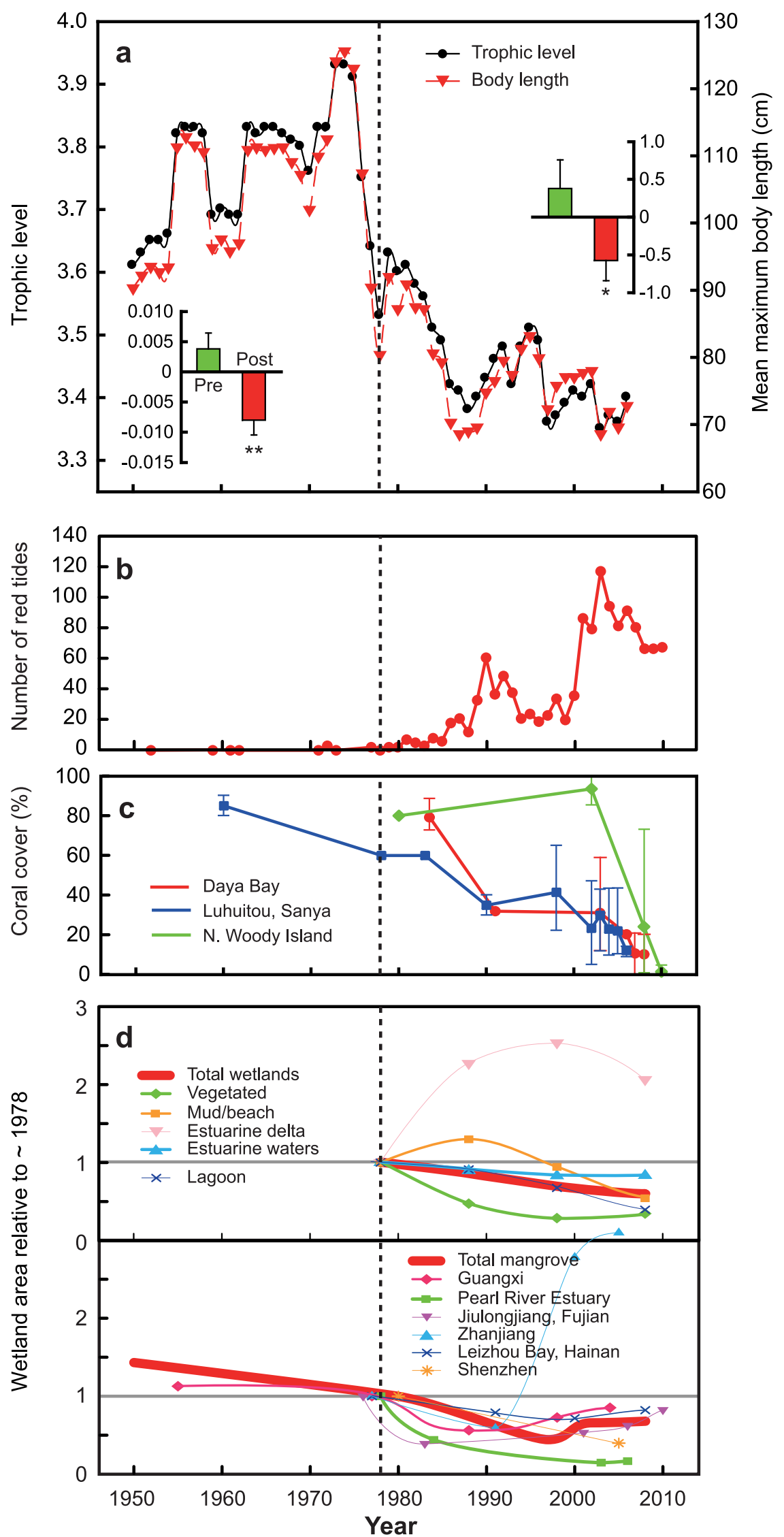

Figure $4 \mid$ Historical trends in coastal ecosystem responses to human impacts. (a) Change of fish trophic diversity and body length; insets are the annual rates ( + SE) of change pre- and post-economic reform. (b) Number of red tides recorded/year. (c) Mean coral cover (error bars for maximums and minimums) at three sites, South China. (d) Loss of coastal wetlands, shown as relative area of total wetlands (upper) and mangroves (lower). Wetland area in $\sim 1978$ (1976-1980) was set to be 1. 
autoregressive terms, and checked if the coefficients were significant $(P<0.05)$. Insignificant terms were removed one at a time (from $\beta_{3}$ to $\beta_{0}$ ) and coefficients were re-estimated. We checked if residuals of the model were white noise using correlogram - Q statistics and Durbin-Watson statistics $(\sim 2)$. Autoregressive and movingaverage terms were included and coefficients were re-estimated when necessary.

Cross-sectional analysis: The same nine impacts [EEZ fish catch (unavailable at regional scales) was replaced by coastal sewage] were used as impact intensity. Impact intensity was estimated as their total amount averaged over 2001-2010 (2001-2007 for $\mathrm{CO}_{2}$ emissions) divided by total land area (for excess fertilizers and $\mathrm{CO}_{2}$ emissions) or mainland coastline length (for the other seven human impacts). A summary of the cross sectional data can be found in Supplementary Table S2. We used ordinary least square regressions to estimate the coefficients of the following EKC model:

$$
\ln y_{i}=\beta_{0}+\beta_{1} \ln x_{i}+\beta_{2}\left(\ln x_{i}\right)^{2}+\beta_{3}\left(\ln x_{i}\right)^{3}+\varepsilon_{i}
$$

where $i$ is the cross section (province of China)

Panel analysis: The matrix of each impact had two dimensions year and province. A summary of the panel data can be found in Supplementary Table S2. The following EKC model was estimated:

$$
\ln y_{i t}=\alpha_{i}+\beta_{1} \ln x_{i t}+\beta_{2}\left(\ln x_{i t}\right)^{2}+\beta_{3}\left(\ln x_{i t}\right)^{3}+\varepsilon_{i t}
$$

where $\alpha$ is the individual effect assumed to be constant over time $t$ and specific to province $i$, i.e., the fixed-effects approach. We used the fixed-effects rather than the random-effects approach, because the fixed-effects approach has been more widely used $^{22}$ and preliminary analysis using Hausman tests (see ref. 22) showed that the null hypothesis of the random-effects approach that the individual effects are uncorrelated with other regressors was generally rejected at the level of $P<0.05$.

Historical trends in coastal degradation. To quantify historical changes in coastal ecosystems, we gathered data from published datasets and primary literature for the following five categories of response: (i) sea physical environment, (ii) depletion of fishery resources, (iii) algal blooms, (iv) degradation of corals, and (v) loss of coastal wetlands. Details are given in Supplementary Methods. This information was collected from databases, or by thoroughly searching the primary literature on China Knowledge Resource Integrated Database (CNKI, www.cnki.net; which includes papers published in the majority of China's science journals, Ph.D. and master theses) and Web of Science and extracting data from tables, text or figures. Search items, criteria for selecting studies and all retained studies are provided in Supplementary Table S3.

1. United Nations Environment Programme. Marine and Coastal Ecosystems and Human Wellbeing: A Synthesis Report Based on the Findings of the Millennium Ecosystem Assessment (UNEP, Nairobi, Kenya, 2006)

2. Barbier, E., Hacker, S., Koch, E., Stier, A. \& Silliman, B. R. The value of estuarine and coastal ecosystem services. Ecol. Monogr. 81, 169-193 (2011).

3. Gallup, J. L., Sachs, J. D. \& Mellinger, A. D. Geography and economic development. Int. Reg. Sci. Rev. 22, 179-232 (1999).

4. Lotze, H. K. et al. Depletion, degradation, and recovery potential of estuaries and coastal seas. Science 312, 1806-1809 (2006)

5. Mora, C. et al. Global human footprint on the linkage between biodiversity and ecosystem functioning in reef fishes. PLoS Biol. 9, e1000606 (2011).

6. Perry, R. I. et al. Marine social-ecological responses to environmental change and the impacts of globalization. Fish Fish 12, 427-450 (2011).

7. Myers, R. A. \& Worm, B. Rapid worldwide depletion of predatory fish communities. Nature 423, 280-283 (2003).

8. Hughes, T. P. et al. Climate change, human impacts, and the resilience of coral reefs. Science 301, 929-933 (2003).

9. Wolff, W. J. The end of a tradition: 1000 years of embankment and reclamation of wetlands in the Netherlands. Ambio 21, 287-291 (1992).

10. Jorgenson, A. K. Economic development and the carbon intensity of human wellbeing. Nature Clim. Change 4, 186-189 (2014).

11. Ehrlich, P. R., Kareiva, P. M. \& Daily, G. C. Securing natural capital and expanding equity to rescale civilization. Nature 486, 68-73 (2012).

12. Turra, A. et al. Global environmental changes: setting priorities for Latin American coastal habitats. Global Change Biol. 19, 1965-1969 (2013).

13. Arrow, K. et al. Economic growth, carrying capacity, and the environment. Science 268, 520-521 (1995)

14. Stern, D. I., Common, M. S. \& Barbier, E. B. Economic growth and environmental degradation: the environmental Kuznets curve and sustainable development. World Dev. 24, 1151-1160 (1996).

15. Saboori, B., Sulaiman, J. \& Mohd, S. Economic growth and $\mathrm{CO}_{2}$ emissions in Malaysia: A cointegration analysis of the Environmental Kuznets Curve. Energ. Policy 51, 184-191 (2012).

16. Galeotti, M., Lanza, A. \& Pauli, F. Reassessing the environmental Kuznets curve for $\mathrm{CO}_{2}$ emissions: A robustness exercise. Ecol. Econ. 57, 152-163 (2006).

17. Diao, X. D., Zeng, S. X., Tam, C. M. \& Tam, V. W. Y. EKC analysis for studying economic growth and environmental quality: a case study in China. J. Clean. Prod. 17, 541-548 (2009).

18. Fodha, M. \& Zaghdoud, O. Economic growth and pollutant emissions in Tunisia: an empirical analysis of the environmental Kuznets curve. Energ. Policy 38, 1150-1156 (2010).
19. Culas, R. J. Deforestation and the environmental Kuznets curve: an institutional perspective. Ecol. Econ. 61, 429-437 (2007).

20. Bhattarai, M. \& Hammig, M. Institutions and the Environmental Kuznets Curve for deforestation: a cross-country analysis for Latin America, Africa, and Asia. World Dev. 29, 995-1010 (2001).

21. Luzzati, T. \& Orsini, M. Investigating the energy-environmental Kuznets curve. Energy 34, 291-300 (2009).

22. Yoo, S. \& Lee, J. Electricity consumption and economic growth: a cross-country analysis. Energ. Policy 38, 622-625 (2010)

23. Aslanidisa, N. \& Iranzo, S. 2009. Environment and development: is there a Kuznets curve for $\mathrm{CO}_{2}$ emissions? Appl. Econ. 41, 803-810 (2009).

24. Kanbur, R. \& Zhang, X. Fifty years of regional inequality in China: a journey through central planning, reform, and openness. Rev. Dev. Econ. 9, 87-106 (2005).

25. Holz, C. A. China's economic growth 1978-2025: what we know today about China's economic growth tomorrow. World Dev. 36, 1665-1691 (2008).

26. Chen, A. \& Groenewold, N. Reducing regional disparities in China: an evaluation of alternative policies. J. Comp. Econ. 38, 189-198 (2010)

27. Huang, Z. \& Lin, M. Marine Species and Atlas in China (Ocean Press, Beijing, 2012).

28. Liu, J. Status of marine biodiversity of the China Seas. PloS ONE 8, e50719 (2013).

29. Wang, Y. Sea-level changes, human impacts and coastal responses in China. J. Coast. Res. 14, 31-36 (1998).

30. Daoji, L. \& Daler, D. Ocean pollution from land-based sources: East China Sea, China. Ambio 33, 107-113 (2004).

31. Cao, W. \& Wong, M. H. Current status of coastal zone issues and management in China: a review. Environ. Int. 33, 985-992 (2007)

32. Jackson, J. B. C. et al. Historical overfishing and the recent collapse of coastal ecosystems. Science 293, 629-637 (2001).

33. Halpern, B. S. et al. A global map of human impact on marine ecosystems. Science 319, 948-952 (2008).

34. State Oceanic Administration China. Bulletin of China Marine Economy 2010 (2011). http://www.soa.gov.cn/zwgk/hygb/.

35. Yu, H. \& Yu, Y. Fishing capacity management in China: theoretic and practical perspectives. Mar. Pol. 32, 351-359 (2008).

36. Cole, M. A. Trade, the pollution haven hypothesis and the environmental Kuznets curve: examining the linkages. Ecol. Econ. 48, 71-81 (2004).

37. Ip, C. C. et al. Over one hundred years of trace metal fluxes in the sediments of the Pearl River Estuary, South China. Environ. Poll. 132, 157-172 (2004).

38. Guo, Z., Lin, T., Zhang, G., Yang, Z. \& Fang, M. High-resolution depositional records of polycyclic aromatic hydrocarbons in the central continental shelf mud of the East China Sea. Environ. Sci. Technol. 40, 5304-5311 (2006).

39. Chen, T. R. et al. Heavy metal pollution recorded in Porites corals from Daya Bay, northern South China Sea. Mar. Environ. Res. 70, 318-326 (2010).

40. Russell, B. D., Thompson, J. A. I., Falkenberg, L. J. \& Connell, S. D. Synergistic effects of climate change and local stressors: $\mathrm{CO}_{2}$ and nutrient-driven change in subtidal rocky habitats. Global Change Biol. 15, 2153-2162 (2009).

41. Brady, D., Kaya, Y. \& Beckfield, J. Reassessing the effect of economic growth on well-being in less-developed countries, 1980-2003. Stud. Comparative Int. Dev. 42, 1-35 (2007)

42. Lotze, H. K., Coll, M. \& Dunne, J. A. Historical changes in marine resources, food web structure and ecosystem functioning in the Adriatic Sea, Mediterranean. Ecosystems 14, 198-222 (2011).

43. Anticamara, J. A. et al. Global fishing effort (1950-2010): trends, gaps, and implications. Fish. Res. 107, 131-136 (2011).

44. Qiu, W., Wang, B., Jones, P. J. S. \& Axmacher, J. C. Challenges in developing China's marine protected area system. Mar. Pol. 33, 599-605 (2009).

45. Zheng, Y. M. et al. Protection efficacy of national wetland reserves in China. Chinese Sci. Bull. 57, 1116-1134 (2012).

46. Halpern, B. S. et al. An index to assess the health and benefits of the global ocean Nature 488, 615-620 (2012).

47. Elfes, C. T. et al. A regional-scale ocean health index for Brazil. PLoS ONE 9 , e92589 (2014).

48. Liang, Z. \& Ma, Z. China's floating population: new evidence from the 2000 census. Popul. Dev. Rev. 30, 467-488 (2004).

49. Hoegh-Guldberg, O. \& Bruno, J. F. The impact of climate change on the world's marine ecosystems. Science 328, 1523-1528 (2010).

50. O’Shea, T. J. \& Odell, D. K. Large-scale marine ecosystem change and the conservation of marine mammals. J. Mammal. 89, 529-533 (2008).

51. Santer, B. D. et al. Statistical significance of trends and trend differences in layeraverage atmospheric temperature time series. J. Geophys. Res. 105 7337-7356 (2000).

52. Yaffee, R. A. \& McGee, M. Introduction to Time Series Analysis and Forecasting with Applications of SAS and SPSS (Academic Press, Inc., New York, 2000).

\section{Acknowledgments}

We thank D.F. Sax, C.B. Craft, S. Crotty and C. Brisson for comments/edits, and J. Huang for China's watershed map. This study was funded by National Key Basic Research Program of China (2013CB430406), China National Funds for Distinguished Young Scientists (51125035), National Science Foundation for Innovative Research Group (51121003) and the Biological Oceanography Program of the National Science Foundation (USA). 


\section{Author contributions}

Q.H., M.D.B. and B.C. conceived and coordinated the research. J.F.B., B.L. and G.C. contributed to the research design. Q.H. collected the data and conducted the analysis. J.F.B., G.C. and S.C.P. contributed to the data sources and analysis. Q.H., M.D.B., T.C.C. and A.H.A. wrote the first draft of the manuscript. J.F.B., B.L., G.C., J.B., T.S., S.C.P., J.L., P.R.E. and B.C. edited the manuscript.

\section{Additional information}

Supplementary information accompanies this paper at http://www.nature.com/ scientificreports

Competing financial interests: The authors declare no competing financial interests.
How to cite this article: He, Q. et al. Economic development and coastal ecosystem change in China. Sci. Rep. 4, 5995; DOI:10.1038/srep05995 (2014).

(c) (1) () () This work is licensed under a Creative Commons Attribution-NonCommercialNoDerivs 4.0 International License. The images or other third party material in this article are included in the article's Creative Commons license, unless indicated otherwise in the credit line; if the material is not included under the Creative Commons license, users will need to obtain permission from the license holder in order to reproduce the material. To view a copy of this license, visit http:// creativecommons.org/licenses/by-nc-nd/4.0/ 